\title{
Akıllı Ulaşım Sistemlerinin Kent İçi Toplu Taşımaya Etkisi: Erzurum İli Örneği
}

\author{
M. Yasin ÇODUR*, Saltuk TOPDAĞI
}

Erzurum Teknik Üniversitesi, Mühendislik ve Mimarlık Fakültesi, İnşaat Mühendisliği Bölümü Erzurum, Türkiye

Geliş / Received: 24/03/2018, Kabul / Accepted: 03/12/2018

$\ddot{\mathbf{O z}}$

Dünya'da ve Türkiye'de gelişmekte olan kentlerde nüfus artışı pek çok soruna yol açmaktadır. Bu sorunlar içerisinde kent içi ulaşım sorunu önemli bir paya sahiptir. Sorunların çözümü için gerekli en temel yöntem hızlı, konforlu, güvenlikli ve ekonomik bir toplu taşıma sistemidir. Ulaştırma alanında yaşanan bu teknolojik yenilikler ve yaşanan ulaşım sorunlarının artık geleneksel yollar ile çözülememesi akılllı ulaşım sistemlerini ortaya çıkarmıştır. Bu çalışma kapsamında Akıllı Ulaşım Sistemleri uygulamalarının toplu taşıma alanında Erzurum İlinde uygulanma düzeyleri incelenmiştir. Bunlara ek olarak Akıllı Ulaşım Sistemlerinin Erzurum İlinde toplu taşıma sistemlerinde kullanımını artıracak uygulamaları ve mevcut durumdaki uygulamaların geliştirilmesine yönelik tavsiyelerde bulunulmuştur.

Anahtar Kelimeler: Akıllı Ulaşım Sistemleri, Gelişmekte olan Ülkeler, Trafik Problemleri, Toplu Taşıma

\section{The Effect of Intelligent Transportation Systems on Urban Public Transport: A Case Study of Erzurum}

\begin{abstract}
Population increase in developing cities leads lots of problems in Turkey and across the world. Among these problems, urban transportation takes a substantial share. The fundamental, fastest, comfortable method to solve existing transportation problems is creating a secure and economic public transportation system. Development of transportation field and unsatisfying conventional methods conduce to developing Intelligent Transportation Systems. Intelligent Transportation Systems have a growing usage in developed cities. In this study, application levels of intelligent transportation systems at public transportation of Erzurum city is investigated. In addition, some applications that could rise the usage of public transportation in Erzurum is examined. Furthermore; some suggestions have been made for the development of existing applications.
\end{abstract}

Keywords: Intelligent Transportation Systems, Developing Countries, Traffic Problems, Public Transportation

\section{Giriş}

Gelişmiş ülkelerde teknolojinin ilerlemesi çoğu alanda olduğu gibi ulaştırma alanına da yenilikler getirmektedir. Bu ülkelerde trafik düzeni içerisinde oluşabilecek karışıklıkları ve hataları düşük seviyelere indirgeyebilmek için ulaştırma hizmetlerinde teknoloji kullanımı artırılmaktadır. Ulaştırma sisteminde teknolojinin bu denli kullanılmaya başlanması Akıllı Ulaşım Sistemlerini (AUS) ortaya çıkarmaktadır. AUS sayesinde kaliteli bir toplu taşıma sistemi elde edilebilmektedir. Böylece insanların toplu taşıma kullanımı artırılarak kentlerdeki trafik sorunu azaltılabilmektedir.
Artan trafik taleplerini sağlıklı bir ulaşım sistemi ile karşılayabilmek için yerel yönetimler ve akademisyenler sürekli çalışmalar yapmaktadır. Ulaşım sorunlarının çözümüne yönelik bazı çalışmalar aşağıda verilmiştir. Çapalı (2009), çalışma alanı olarak dünyada ileri teknolojiye sahip AUS'un uygulama alanlarını incelemektedir. $\mathrm{Bu}$ uygulama alanları içerisinde Türkiye'de kullanılmakta olan bazı trafik yazılımları, karayollarında kullanılan AUS ve uygulamaları yer almaktadır. Yapılan çalışmanın sonucu olarak Türkiye'de kullanılan trafik teknolojilerinin yetersiz olduğu ve AUS kullanımına geçilmesinin 
gerekliliği belirtilmektedir. Köz (2011), çalışmasında 1950'lerden günümüze kadar ülkemizde yapılmış olan ulaştırma politikalarını incelemektedir. Kent içi ulaşım sistemi ve AUS konularını işlemektedir. Dünya'da kullanılan farklı AUS konuları incelenmekte ve İstanbul ili ile karşılaştırma yapmaktadır. Yıldırım (2016), çalışmasında karayolu hizmet devriye yönetimi, geniş alan uyarısı, erken uyarı sistemi, afet müdahale ve kurtarma gibi afet acil durum yönetimi ile ilgili konuları işlemektedir. Afet durumlarında yapılması gereken erken müdahaleleri AUS teknolojilerini kullanarak daha sağlıklı ve daha hızlı yapılabileceği konularını işlemektedir. Shi ve Yang (2013), yaptıkları çalışmada Tayvan'da toplu taşıma sistemlerinde meydana gelen değişiklikleri ve gelişmeleri ele almaktadır. Toplu taşıma sistemlerinin gelişiminde AUS'un kullanım alanları ve toplu taşıma sistemlerinin gelişimine katkıları incelenmiştir. Janusova ve Cicmancova (2015) AUS kullanım alanlarını ve bu sistemlerin ulaşımda meydana getirebileceği trafik güvenliği, verimlilik ve maliyet konuların incelemektedir. Slovakya'da demiryollarının güvenliğini ve verimliliğini artırabilecek çok sayıda teknolojinin varlığını ve bu teknolojilerin Slovakya demiryolları içinde kullanılması gerektiğini ele almaktadır. Kuşkapan vd. (2018) AUS'un bir çalışma alanı olan ak1llı otopark sistemlerini incelemiştir. Yapılan çalışmada bu sistemlerin uygulanması park alanlarının daha verimli kullanılmasını sağlayacak ve dolayısıyla yol kenarı parklanmaların ve trafik sıkışıklığının azalacağı öngörülmüştür. Böylece akan trafik sayesinde toplu taşımanın da hızlanacağından bahsedilmiştir. Elavarasi ve Senthilkumar (2017) çalışmalarında kent içinde park alanlarının kısıtlı olmasının çevreye olumsuz etkilerinden bahsetmişlerdir. Sürücüler park yerlerini ararken, aracın yakıt verimliliğini azaltan ve trafik yönetimi ciddi bir sorun olduğundan trafik sıkışıklığına neden olan yavaş sürüş eğiliminde olması sebebiyle ak1llı park sistemlerinin öneminden bahsetmişlerdir. Güngör ve Erdinç (2017) yaptıkları çalışmada, toplu taşımada kullanılmakta olan İstanbul Kartını otopark ödemelerinde de kullanarak sağlayacağı kolaylıklardan bahsetmiştir. İstanbul açısından daha güvenilir akıllı ulaşım sistemlerinin oluşabileceği amaçlanmıştır. Büyükbaş (2016) büyükşehirlerden biri olan Kayseri İli için toplu taşımada kullanılmakta olan yöntemleri ele almıştır. Toplu taşımada elde edilen verimi artırmak için uygulanabilecek yöntemler değerlendirilmiştir. Özellikle AUS'un öneminden bahsedilmiştir. Toplu taşımaya yönelik akıllı sistemlerin uygulandığ durumda beklenen verimin sağlanabileceğine değinmiştir. Noyes (2014), toplu taşımacılık 21. yüzyılın ilk on yılında arttığından, mevcut ve genişletilmiş altyapı içinde daha fazla insanı harekete geçirme firsatları sağladığından bahsetmiştir. AUS, transit taşımacılı̆̆ 1 geliştirmek, toplu taşıma ve otoyol tesislerini entegre etmek için transit sistemleri ve karayollarını yöneterek bu taşımacılık sorununu ele almaktadır. Son yirmi yılda, gezgin bilgileri, geçiş önceliği, elektronik ücret toplama, paylaşılan veriler ve entegre operasyonlar artan biniciliği, sistem güvenliğini ve verimliliği desteklemektedir. Ayrıca AUS'un güvenliği, mobiliteyi ve çevreyi geliştiren, gezgin bilgileri ve sistem talep yönetimi ile birleşen uygulamaları, sistem sahiplerine, operatörlere ve kullanicilara maliyeti en aza indirirken seyahat seçeneklerini ve yaşanabilirliği arttırdığına değinmiştir. AUS teknolojilerinin yolculuk planlaması ve mod seçimini kolaylaştırmak gibi kişisel ve toplu taşımacılık için çok çeşitli avantajlar sunmaktadır. Olayları, acil durumları ve doğal afetler sırasında ulaştırma sistemlerini yöneterek kamu güvenliği iyileştirmeleri sağladığından bahsetmiştir. Lim (2012), Kore Cumhuriyetinde uygulanmakta olan ak1ll ulaşım sistemlerini incelemiştir. AUS'un 
trafik yönetimi, toplu taşıma, geri ödeme, trafik bilgi dağıtımı, ek trafik bilgileri, akıllı araçlar ve yollar ile kargo taşımacılığı dahil yedi alanda hizmet verdiğinden bahsetmiştir. Toplu taşıma bilgileri ve yolcular için gerçek zamanlı olarak özelleştirilmiş hizmetler sunarak toplu taşımada modal pay oranını ve toplu taşıma kolaylığını geliştirdiğini vurgulamıştır. Pelletier vd. (2011) AUS'da kullanılan akıllı kart otomatik ücret toplama sistemleri, toplu taşıma acenteleri tarafından giderek daha fazla kullanıldığını ve bu kartın temel amacının gelir toplamak olsa da, aynı zamanda yerleşik işlemlerde çok miktarda çok ayrıntılı veri üretiyor olmasına değinmiştir. $\mathrm{Bu}$ veriler, transit sisteminin günlük işleyişinden şebekenin stratejik uzun vadeli planlamasina kadar transit planlayıcılar için çok yararlı olabileceğini vurgulamıştır. $\mathrm{Bu}$ gözden geçirme, toplu taşıma bağlamında akıllı kart veri kullanımının çeşitli yönlerini kapsamaktadır. Akıllı kartla elde edilen verilerin üç yönetim düzeyindeki çeşitli kullanımları tanımlanmıştır: Stratejik (uzun vadeli planlama), taktik (hizmet ayarlamaları ve ağ geliştirme) ve operasyonel (binicilik istatistikleri ve performans göstergeleri). Ayrıca tüm dünyada gerçekleştirilen akıllı kart ticarileştirme deneyleri de rapor edilmiştir. Son olarak, bu alanda akıllı kart verileri için en umut verici araştırma alanları sunulmuştur; bunlara, planlı ve uygulamalı programların karşılaştırılması, sistematik program ayarlamaları ve bisikletçilere uygulanan hayatta kalma modelleri örnek verilebilir. Bahsedilen çalışmalar incelendiğinde yapılan çalışmalar; kent içi ulaşım sorunlarını ele alarak ulaşımda verimi artırabilecek yöntemlere değinilmiştir. Özellikle gelişen teknoloji ile birlikte akıllı ulaşım sistemleri hayatımıza girmiş ve birçok fayda sağlamıştır. $\mathrm{Bu}$ çalışmada ise Türkiye'nin metropol kentlerinde ciddi boyutlarda yaşanan ulaşım sorunları çözümünde izlenilen yollara ve bu kentlerde ya da dünyada kullanımı gittikçe yaygınlaşan
AUS uygulamalarının Erzurum'da kent iç ulaşım sorunlarının çözümüne yönelik uygulamaları incelenmiştir. $\mathrm{Bu}$ incelemelerle birlikte Erzurum'da toplu taşıma kullanımını artırmak amaçlı yeni AUS uygulamalarının kullanılması ve yetersiz düzeyde kalmış bazı mevcut olan uygulamaların geliştirilmesine yönelik öneriler sunulmuştur (Topdağı,2017).

\section{Materyal ve Metot}

\subsection{Materyal}

Erzurum kent nüfusu 2016 y1lı itibariyle 762 000 kişi ve yüz ölçümü bakımından 25355 $\mathrm{km}^{2}$ ile Doğu Anadolu Bölgesinin en büyük kenti olma özelliğine sahiptir. Kent içinde bireylerin yoğun bir şekilde özel araçlarını kullanma istekleri sonucunda kentin en önemli arterlerinde trafik akışında tıkanıklıklar meydana gelmektedir. Arterlerde meydana gelen bu trafik tıkanıklığı sonucunda bağlantı yolları istenilen görevi yapamamaktadır. Erzurum kentinde ekonominin gelişmesine paralel olarak özel araç sahipliği artmaktadır. Türkiye İstatistik Kurumu 2006 verilerine göre Erzurum'daki otomobil sayısı 30055 adettir. Yine Türkiye İstatistik Kurumu Mart 2017 verilerine göre Erzurum iline kayıtlı motorlu kara taşıt sayısı 113404 adet olup bunların $55 \quad 909$ adedini otomobiller oluşturmaktadır. 11 yıllık süreç içerisinde yaklaşık 26000 adet araçlık bu artış 2006 yılındaki otomobil sayısının yaklaşık \%87 fazlasıdır (TÜİK, 2017). Erzurum kentine kayıtlı otomobil sayısındaki bu büyük artış kent içi trafiği olumsuz yönde etkilemektedir. Kent içi yol yapısının genel itibariyle dar olmasına ek olarak bu yol kenarlarına yapılan otomobil parkları ve mevcutta bulunan otoparkların otomobil sürücüleri tarafından maliyetli olarak görülmesi ya da kullanım alışkanlığ 1 olmamasından dolayı kent içinde trafik sorunları yaşanmaktadır. Kent içerisinde Erzincankapı, Havuzbaşı, Numune, Cedit, Aziziye ve Menderes otoparkları bulunmaktadır. $\mathrm{Bu}$ otoparklar toplam 1425 araçlık kapasiteye sahiptir. 
Özellikle Havuzbaşı Kavşağı, Gez Mahallesi Kavşağı, Gürcükapı Kavşağı, Atatürk Üniversitesi Kavşağı ve Yavuz Sultan Selim Bulvarı ile Atatürk Bulvarını birleştiren Yenişehir Kavşağı günün pik saatlerinde trafik tıkanıklı̆ğ yaşamakta ve bu kavşaklara bağlanan yollarda aşırı trafik görülmektedir.

\subsection{Yöntem}

\subsubsection{Akullı Ulaşım Sistemleri}

Akıllı ulaşım sistemleri; seyahat sürelerinin azaltılması, trafik güvenliğinin arttırılması, mevcut yol kapasitelerinin optimum kullanımı, mobilitenin arttrrılması, enerji verimliliği sağlanarak ülke ekonomisine katkıda bulunmak ve çevreye verilen zararın azaltılması gibi amaçlar doğrultusunda geliştirilen, kullanıcı-araç-altyapı-merkez arasında çok yönlü veri alışverişi ile izleme, ölçme, analiz ve kontrol içeren sistemlerdir. Akıllı ulaşım sistemleri ulaşımda çevresel etkileri azaltacak şekilde hareketliliği ve güvenliği arttırarak ulaşımı destekleyen gelişmiş bilgi ve iletişim teknoloji uygulamaları olarak tanımlanabilir. Karayolu; araç, sürücü, altyapı ve diğer ilgili bileşenlerin bilgi ve iletişim teknolojileriyle donatılarak, verimli ve güvenli biçimde işletilmesini ve kullanılmasını sağlayan sistemlerdir. Akıllı ulaşım sistemleri üzerine yapılan araştırmaların hedefi ulusal, çok modlu ulaşım sistemlerini geliştirmektir. Bu kapsamda ele alınan konular ise; her türlü taşıtın birbirleriyle, altyapı ve cihazlarla bağlanabilen bir ulaşım ortamı oluşturması ve topluma ulaşım hizmetini sunarken güvenliği, hareketliliği ve çevresel performansı maksimize edecek teknolojileri geliştirmektir. Araçlar ve yollardaki sensör ve cihazların birbirleri ile iletişim kuracağı düşünüldüğünde AUS'un M2M (Machine-tomachine / makineler arası iletişim) veya IoT
(Internet of Things-nesnelerin interneti) olduğu söylenebilir.

AUS temel olarak aşağıdaki alanlarda kullanılmaktadır;

- Ücretlendirme sistemleri

- Park sistemleri

- Trafik kontrolü

- Trafik planlama ve akışın optimizasyonu

- Sürüş güvenliği

Dünyada gelişmiş ülkelerin birçoğu AUS alanında önemli mesafeler kat etmiş olsa da Türkiye'de özellikle bulundukları coğrafi bölgelerin ticari ve sosyal açıdan cezbedici önemli kentlerinde artan nüfus ve araç miktarı bu kentlerde son yıllarda AUS uygulamalarının kullanımını ortaya çıkarmaktadır.

\section{Bulgular ve Tartış̧a}

Ulaştırma kalitesi, bir ülkenin refah seviyesini gösterebilen ve aynı zamanda ekonomik gelişimi yansıtabilen en önemli etkenlerden birisidir. Günümüz teknolojisinin gelişmesine paralel olarak küreselleşme ve ekonomik büyüme ile birlikte ulaşımda hızlı bir değișim göstermektedir. Nüfus artışı ve büyüyen kentleşmeler ile birlikte artan araç sayısı sonucunda bireylerin daha konforlu, hızlı ve güvenilir ulaşım ihtiyaçları da artmaktadır. Türkiye'de 2006-2016 yılları arasındaki motorlu kara taşı sayıları Şekil 1'de gösterilmiştir. Yıllara göre motorlu taşıt sayılarında devamlı bir artış görülmektedir. Buna sebep olan en önemli faktör artan nüfus sayısıdır. Diğer önemli faktörler ise özel araç sahipliğine olan talebin ve insanların refah düzeylerinin artması olarak söylenebilir. 
25.000 .000

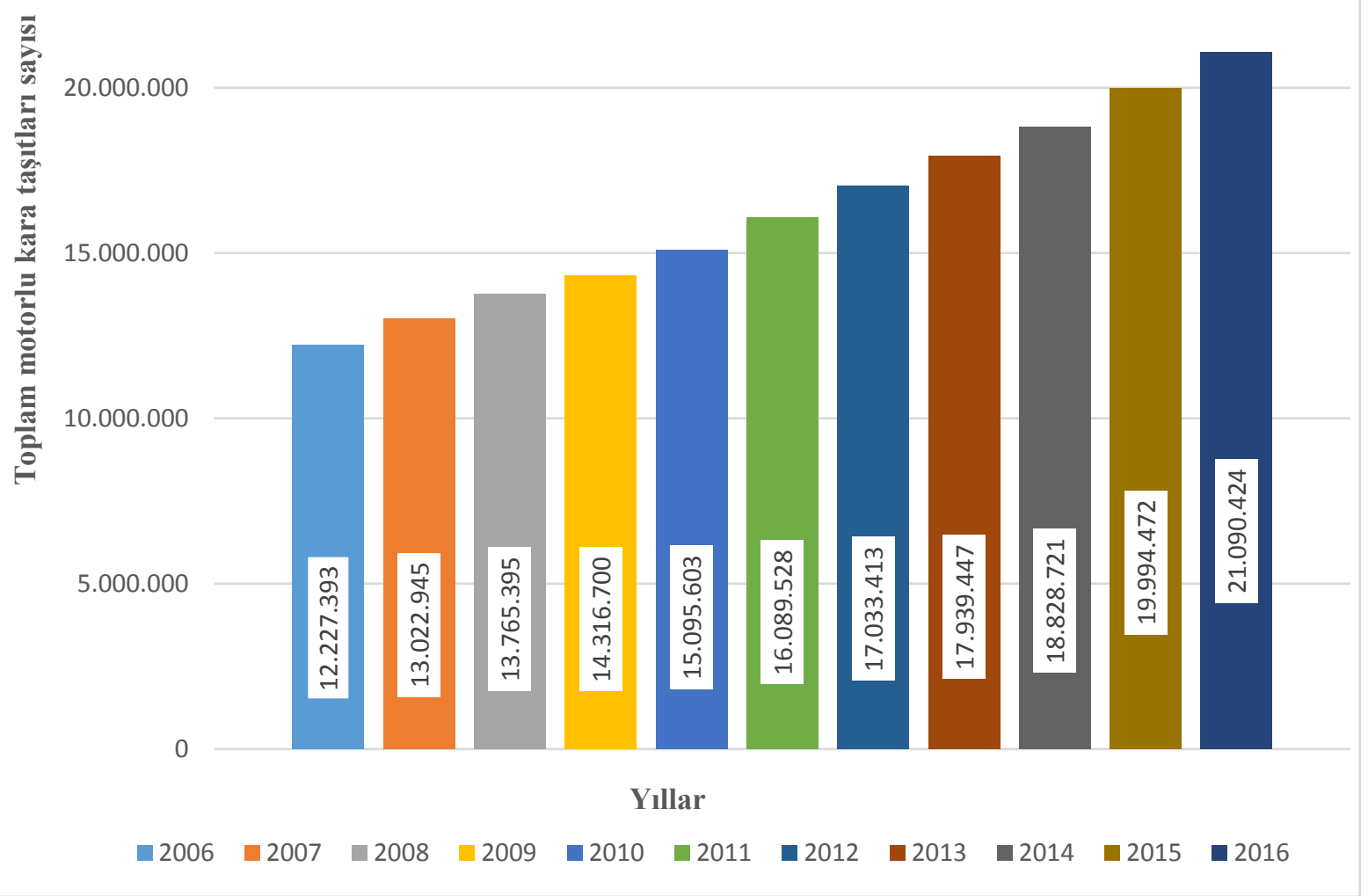

Şekil 1. Türkiye'de yıllara göre motorlu kara taşıtları sayısı artış grafiği (TÜİK, 2017).

Artan nüfus ve araç sayısı nedeniyle kent içi trafik akımında tıkanmalar meydana gelmektedir. $\mathrm{Bu}$ artış kent içerisinde trafik kazaları oranını da arttırmaktadır. Trafik kazalarından kaynaklanan yaralanmaları ve ölüm oranlarını azaltabilmek ve araç içinde, araç dışında, araç ile sabit kontrol merkezleri arasında, ayrıca altyapı hakkında, emniyet, güvenlik, randıman ve kalite bakımından her türlü haberleşmeyi ve bilgi alışverişini sağlayabilmek için AUS adında kontrol ve denetim mekanizması kurulmuştur. Dünyada birçok ülke, AUS programlarını ulusal düzeyde hazırlamış ve AUS projelerinin kaynağını yerel düzeyde sağlamıştır. Ekonomik olarak gelişmiş olan ülkeler AUS konusundaki çalışmalarını gün geçtikçe ileriye taşımaktadır. Tablo 1 incelendiğinde ülkelerin AUS çalışmalarının yıllara göre değişimi belirtilmiştir. Bu konuda ilk çalışma 1963 yilında Avustralya tarafindan koordineli çalışan bir trafik sistemi ile başlamıştır. Diğer gelişmiş ülkelerde AUS uygulamalarına yönelik çalışmaları doğrultusunda günümüze kadar gelişmesini sürdürmektedir. Bir ülkede yapılmış olan çalışmanın diğer ülkeler tarafindan daha ileriye götürülüyor olması sayesinde günümüzde birçok trafik problemi AUS tarafindan çözüm bulunmaktadır. Aynı şekilde günümüzde büyük bir sorun olabilen bir durum AUS sayesinde yakın tarihte basit bir şekilde çözüme kavuşabilecektir. 
Tablo 1. Gelişmiş bazı ülkelerde Akıllı Ulaşım Sistemlerinin yıllara göre gelişim aşamalar (Nowacki, 2012; Lee, 2012; Hanai,2013).

\begin{tabular}{|c|c|c|c|c|c|}
\hline BÖLGE & TARİH & AUS AŞAMALARI & BÖLGE & TARİH & AUS AŞAMALARI \\
\hline Avustralya & 1963 & $\begin{array}{l}\text { Sidney Koordineli Adaptif } \\
\text { Trafik Sistemi }\end{array}$ & $\mathrm{ABD}$ & 1990 & $\begin{array}{l}\text { Akıllı Araç Otoyol } \\
\text { Sistemleri }\end{array}$ \\
\hline Avustralya & 1970 & Trafiğe Duyarlı Kabiliyetler & $\mathrm{ABD}$ & 1991 & $\begin{array}{l}\text { İntermodal Ulaştırma } \\
\text { Verimliliği Yasasının } \\
\text { Kabulü }\end{array}$ \\
\hline Avustralya & 1985 & $\begin{array}{l}\text { Trafiğe Duyarlı Adaptif } \\
\text { Kontrol Sistemi }\end{array}$ & Japonya & 1973 & $\begin{array}{l}\text { Kapsamlı Otomobil Kontrol } \\
\text { Sistemi }\end{array}$ \\
\hline Avrupa & 1974 & $\begin{array}{l}\text { Sürücü Radyo Yayını } \\
\text { Bilgilendirme Sistemi }\end{array}$ & Japonya & 1984 & $\begin{array}{l}\text { Karayolu/ Araç } \\
\text { Haberleşme Sistemi }\end{array}$ \\
\hline Avrupa & 1986 & $\begin{array}{l}\text { Yüksek Verimli ve Eşsiz } \\
\text { Emniyetli Avrupa Trafik } \\
\text { Sistemi Programı } \\
\end{array}$ & Japonya & 1987 & $\begin{array}{l}\text { Gelişmiş Mobil Trafik } \\
\text { Haberleşme ve Bilgi Sistemi }\end{array}$ \\
\hline Avrupa & 1989 & $\begin{array}{l}\text { Avrupa'da Araç Emniyeti için } \\
\text { Adanmış Karayolu Altyapısı }\end{array}$ & Japonya & 1990 & $\begin{array}{l}\text { Araç Haberleşme ve Bilgi } \\
\text { Sistemi }\end{array}$ \\
\hline Avrupa & 1991 & $\begin{array}{l}\text { Trafik Verimliliği ve Emniyeti } \\
\text { için Hücresel Radyo Sistemi }\end{array}$ & Japonya & 2012 & İleri Mobil Bilgi Sistemleri \\
\hline Avrupa & 1991 & $\begin{array}{l}\text { Avrupa Karayolu Ulaştırması } \\
\text { Telematikleri Uygulama } \\
\text { Koordinasyonu }\end{array}$ & Japonya & 2013 & $\begin{array}{l}\text { Hızlı Acil Durum Müdahale } \\
\text { Araçlarını Öne Alım } \\
\text { Sistemleri }\end{array}$ \\
\hline Avrupa & 1991 & Ulaştırma Telematikleri & $\begin{array}{l}\text { Güney } \\
\text { Kore }\end{array}$ & 1992 & $\begin{array}{l}\text { Otoyol Trafik Yönetim } \\
\text { Sistemi }\end{array}$ \\
\hline Avrupa & 1994 & Trafik Mesaj Kanalı & $\begin{array}{l}\text { Güney } \\
\text { Kore }\end{array}$ & 1997 & $\begin{array}{l}\text { Gelişmiş Trafik Kontrol } \\
\text { Sistemi ve Pilot Projesi }\end{array}$ \\
\hline $\mathrm{ABD}$ & 1990 & Akıllı Araç Otoyol Sistemleri & $\begin{array}{l}\text { Güney } \\
\text { Kore }\end{array}$ & 2000 & $\begin{array}{l}\text { Otomatik Ücret Toplama } \\
\text { Sistemi }\end{array}$ \\
\hline
\end{tabular}

\subsection{Türkiye'de AUS Uygulamaları}

1992 yılında kullanılmaya başlanan "Otoyol Ücret Toplama Sistemi” ülkemizde AUS' a girişin ilk adımları olarak düşünülebilir. Özellikle İstanbul gibi büyük ve kalabalık kentlerde köprü geçişlerinde beklemeden dolayı yaşanan zaman kaybını önlemek için 1999 yılında Otomatik Geçiş Sistemi (OGS) kullanılmaya başlanmıştır. Operatörlü olarak kullanılan bu sistem araçların otoyolda aldıkları mesafeye göre ve araç sınıflarına göre ücretlendirme çalışması yapmaktadır. Ek olarak acil durum yönetim sistemleri de otoyollarda işletilmektedir. Özel sektörlerin de AUS alanına ilgi göstermesiyle hız sınırı işaretleri, plaka tespit sistemleri, radar sistemleri, değişken trafik işaretleri gibi uygulamalar otoyollarda kullanılmaya başlanmıştır (Yardım ve Akyıldız, 2004).
Yapılan araştırmalarda AUS uygulamalarının genellikle mevzuat ve politikanın ilerisinde gittiği görülmektedir. İlk önce teknolojiler geliştirilmiş, daha sonra bu teknolojiyi kullanmak için uygulamalar yapılmıştır. Sadece o uygulamaların yerel kullanımda olmaktan çıkıp yaygın kullanıma başlamasından sonra uygulamanın kullanım politikası, düzenlenmesi ve yönetmelikleri ortaya çıkmaktadır. Bu nedenden dolayı bazı uygulamalar ile daha önce karşılaşılmadığı için net bir şekilde gruplandırılamamaktadır. Türkiye'de akıllı ulaşım sistemleri konusunda öncülük eden ilimiz İstanbul'dur. Sahip olduğu çeşitli toplu ulaşım sistemleri ve geniş ağının bulunması AUS'a olan ihtiyacı iyice artırmaktadır. Bu doğrultuda İstanbul Büyükşehir Belediyesi cep trafik uygulamas1 sayesinde tüm trafik ağına, toplu taşıma aktarma durumlarına ve trafik yoğunluğuna ulaşılabilmektedir. Bu sayede 
kullanıcılar tarafindan vakitlerini daha iyi kullanabilmeleri sağlanmış olacaktır. Uygulamanın maliyetine nispeten kullanıcılarına büyük faydalar verecektir. Benzer şekilde Ankara Büyükşehir Belediyesi EGO mobil uygulamasi da toplu ulaşım adına birçok kolaylık sağlamaktadır. Trafik yönetim sistemleri, toplu taşımaya yönelik ak1llı sistemler, IETT araç takip ve yolcu bilgilendirme sistemi (AKYOLBİL), elektronik ücret toplama sistemleri, radyo frekansı ile tanımlama sistemi (RFID), yük ve filo yönetim sistemleri, kaza ve acil durum yönetim sistemleri, demiryolları işletim ve yönetimi, otomatik tren durdurma sistemi (ATS), tren denetim sistemi, tren denetim bilgisayarı, hiz algılama sistemi, hemzemin geçit izleme sistemi, tren bilgi sistemi ve kontrol merkezi, sürücü destek ve güvenlik sistemleri şeklinde sıralanabilir. Öte yandan akı1lı şehircilik parolasıyla Bursa Büyükşehir Belediyesi tarafından yapılmış olan akıllı ulaşım web sayfası sayesinde park alanları trafik yoğunluk haritalarına ulaşmak ve toplu taşıma adına kolaylıklar sağlamaktadır. Ayrıca akıllı duraklar sayesinde toplu taşımada otobüs hatları ile ilgili bilgilere ulaşmak mümkündür. $\mathrm{Bu}$ şehirlere ek olarak Antalya Büyükşehir Belediyesi, Kayseri Büyükşehir Belediyesi, Gaziantep Büyükşehir Belediyesi ve Sakarya Büyükşehir Belediyesi de akıllı şehirler kapsamında AUS'a yönelik çalışmalarını sürdürmektedir. (Bursa Büyükşehir Belediyesi, 2018).

\subsection{Erzurum Toplu Taşıma Sistemlerinde AUS Kullanımı}

\subsubsection{Erzurum Kardelen Kart}

Kent içi toplu taşıma sistemleri içerisinde bulunan belediye ve halk otobüslerinde kullanılmakta olan akıllı kart uygulaması Kardelen kart, yolcuların ücretlerini araçlarda bulunan kart okuyucu sistemlere yaklaştırarak ödemesi şeklinde gerçekleştirilen elektronik ücret toplama sistemidir. $\mathrm{Bu}$ sistem yolcuların ulaşım standartları açısından konforunu artırarak kolay bir ödeme sistemi sağlamaktadır.

\subsubsection{Erzurum Mobil Uygulamast}

Erzurum'da kullanılmakta olan ve akıllı bilet uygulamasına entegre olarak çalışan "Erzurum Mobil" ak1llı telefon uygulamas1 kent içi toplu taşıma sistemleri içerisinde bulunan otobüsler için kullanılmaktadır. Bu uygulama sayesinde yolcular duraklara gelmeden önce binecekleri otobüsün anlık olarak nerede olduğunu görebilmektedirler. Böylece duraklarda aşırı yolcu birikmesi ve özellikle kış mevsim şartlarının çok sert geçtiği Erzurum'da durakta bekleme süresi azaltılarak toplu taşımayı kullanacak yolcular için konfor arttırılmaktadır.

\subsubsection{Erzurum Akıllı Duraklar}

Özellikle kış mevsim şartlarının çok sert geçtĭgi Erzurum'da toplu taşıma kullanıcılarının en çok sıkıntı çektiği konulardan birisi de durakta geçirilen süredir. Çok kısa sürelerin bile çok fazla önem kazandığı soğuk hava şartlarında toplu taşıma kullanıcıları için Erzurum Büyükşehir Belediyesi tarafindan akıllı durak uygulamasına geçilmiştir. Akıllı duraklarda güvenlik 7/24 kameralar ile sağlanmaktadır. Erzurum kent içi toplu taşıma sistemleri konusunda gelişmeye açık olan bir kent durumundadır. Kent merkezinde ara toplu taşıma araçları olarak adlandırılan minibüsler de görev yapmaktadır. Minibüs ve otobüslerin kent içerisinde sürekli bir arada çalışmaları artan taşıt sayısı ve özellikle kent içerisinde yolların dar olması da göz önüne alındığında şehir içerisinde çoğu kavşak noktasında tıkanıklar meydana gelmektedir. Çağdaş toplu taşıma sistemleri içerisinde ara toplu taşıma aracı olarak kullanılması gereken minibüsler Erzurum'da kendi görevlerinden çok daha fazlasını yapmaya çalışmalarından dolayı kaliteli bir toplu taşıma sistemi içerisinde var olması gereken konfor, güvenlik ve hiz gibi önemli 
kriterlerden ödün vermektedirler. Toplu taşıma çeşitliliğin düşük düzeylerde kalmasına ek olarak Erzurum halkının toplu taşıma kullanma tercihinin çok az düzeylerde olması, kent içi trafiğinde karmaşıklıklara sebep olmaktadır. Toplu taşıma hizmetleri memnuniyet araştırmasında Erzurum toplu taşıma sistemi 50,4 puan alarak ülke sıralamasında 62. sirada yer almaktadır (TÜIK, 2013). Özellikle minibüs sisteminde durak harici yapılan yolcu indirip bindirmeler ve araç kapasitesinin düşük olması sebebiyle ayakta kalan yolcular gibi sorunlar kent içinde trafik düzenini tehlikeye sokmaktadır. Gelişmiş ülkelerde trafik düzeninin sağlanması için gerekli olan en etkili faktör kullanımı gittikçe yaygınlaşan AUS' dur. Türkiye AUS konusunda gelişmekte olan bir ülke konumunda olup bu sistemlerin kullanılma oranı özellikle son yıllarda büyük kentlerde artmaya bașlamıștır. Özellikle son yıllarda kent içinde ulaştırma sorunları yaşayan Erzurum, aşırı kişisel araç kullanımından ve kötü hava şartlarından kaynaklı trafik problemleri yaşamaktadır. Yaşanan bu trafik problemlerinde etkili olan faktörler genellikle diğer kentlerde de olduğu gibi şehir imar planlarının daha önceden hatalı düzenlenmesi ve gelecek yılların tahmin planlaması yapılmadan imar aşamasına geçilmesinden kaynaklanmaktadır. $\mathrm{Bu}$ çalışma kapsamında Erzurum kent içi trafik problemlerinin çözümünün toplu taşıma kullanımını artırmak olduğu görülmüştür. Bu kapsamda Erzurum ilinin gelişen şehirler seviyesini yakalayabilmesi ve çağdaş toplu taşıma kullanımının kent içinde yer edinebilmesi için gerekli öneriler belirtilmeye çalışılmıştır. Dünyanın gelişen ülkelerinde ve şehirlerinde olduğu gibi çağdaşılık kavramının toplu taşıma alanında AUS ile birleştirildiği görülmektedir. Günümüzde nüfus yoğunluğunun fazla olduğu ve gelişmekte olan kentlerde AUS kullanımı zorunlu bir hale gelmektedir. Erzurum Büyükşehir Belediyesi tarafından geliştirilen "Erzurum Mobil" uygulaması toplu taşıma alanında vatandaşlara hizmet vermektedir. $\mathrm{Bu}$ uygulama otobüs hathareket saatleri, beklenilen otobüsün konumu ve Kardelen kart bakiye sorgulama gibi özellikler barındırmaktadır. Ancak otomobil ve diğer taşıt sürücüleri için trafiğin yollarda ve kavşaklarda anlık sıkışıklık durumunu gösteren, yolların kaza veya onarım durumunu gösteren ve alternatif yollar sunan bir bilgilendirme özelliği bulunmamaktadır. Mevcutta bulunan mobil uygulamanın geliştirilmesi gerekmektedir. Kış mevsim şartlarının çok sert geçtiği Erzurum kentinde yollarda meydana gelen buzlanma sonucunda çok sayıda toplu taşıma aracı ve özel araç trafik kazalarına maruz kalmaktadır ve bu da trafikte tıkanıklığa yol açmaktadır. Toplu taşıma sisteminde aranılan en önemli niteliklerden birisi olan konfor faktörü kötü hava koşullarının neden olduğu kazalar nedeniyle seyir süresi ve durakta araç bekleme süresinin artmasıyla olumsuz yönde etkilenmektedir. Kış mevsimlerinde mevcut düzende yol temizleme çalışmaları kamyon üzerinden yola tuz serpme olarak bilinen geleneksel yöntemler ile yapılmaktadır. Ancak bu yöntem hem işçilik hem de maliyet açısından yetersiz kalmaktadır. İstanbul Büyükşehir Belediyesi tarafından kullanılan Buzlanma Önleme Sisteminin Erzurum ili içinde uygulanması gerekmektedir. Bu sistem içerisinde otomatik bildirim uyarıları, otomatik buz önleyici sensörler aracilığıyla yola serpilen solüsyonlar ve yol yüzey durum sensörleri bulunmaktadır. Buzlanma önleyici sistemde yol yüzeyi sıcaklığının otomatik algilayıcılar ile algılanarak yol üzerinde buz oluşumunu ve karın yol yüzeyine yapışmasını engelleyen kimyasal bir sıvı kullanılmaktadır. Manuel ve otomatik olarak çalışabilen bu sistem ile donma noktasını düşüren kimyasal maddelerin, yağış başladığı anda ya da öncesinde yol yüzeyine uygulanmasıyla kar veya buz ile yüzey arasında bir bağ kurulması engellenmekte ve sonrasında periyodik kısmi tekrarlar ile etkisini sürdürmesi sağlanmaktadır. 
Meteoroloji Gözlem Sensörleri ile anlık yol ve hava durumu bilgilerinin Değişken Mesaj Sistemi (DMS), 1şıklı trafik levhaları, SMS ve internet vasitası ile sürücülere iletilmesi, ana ulaşım ağlarında oluşabilecek yağış ve buzlanmaların olumsuz etkilerini engellemek için, erken buzlanma zamanı ve kalınlığı tahmini ile yağış miktarı tespiti yapılabilmektedir. Kar küreme araçlarına adapte edilen Vpad teknolojisi ile buzlanma tahmin edilen bölgeye araçların daha hızlı yönlendirilmeleri ve kullanacakları tuzsolüsyon miktarının önceden otomatik olarak belirlenmesi gibi çok önemli uygulamalar Erzurum ilinde kış mevsiminde kullanılması durumunda çok sayıda trafik kazasının önüne geçilecektir. Kış mevsim şartlarının çok sert geçtiği Erzurum'da akıllı durak sistemi Erzurum Büyükşehir Belediyesi tarafından hizmete sunulmuştur. Ancak bu hizmetin kentin geneline hitap etmemesinden dolay çoğu otobüs ve minibüs duraklarında soğuk hava şartlarında insanlar uzun süre toplu taşıma aracı beklemektedirler. Erzurum toplu taşıma kullanımının artırılması için gerekli etkenlerden birisi de mevcut durumda bulunan akıllı durak miktarını artırmaktır. Her durak artışı daha fazla yolcuya hitap edeceğinden konfor seviyesi yükselecek ve toplu taşıma kullanımı artacaktır. Durak miktarlarının artırılmasına ek olarak durakta bekleyen yolcular için konfor düzeyi artırılmalıdır. Her akıllı durakta sadece klimalı ortam değil aynı zamanda teknoloji açısından yeterli seviyede bilgi sistemleri kurulmalıdır. Duraktan geçen otobüs hatlarının numaraları, gidiş güzergâhları, gelecek olan aracın engelli kullanımına uygun olup olmadığ 1 , Kardelen kart için dolum otomatları, ücretsiz internet kullanımı, akülü araçla durağa gelen engelli yolculara şarj imkânı ve görme engelli yolcular için bas-konuş sesli bilgilendirme butonları gibi teknolojilerin Erzurum'da akıllı duraklarda bulunması gerekmektedir. Özellikle otobüs ile toplu taşımanın çok yoğun olarak kullanıldığ Erzurum'da otobüslerin kent içi trafiğinde tecritli olarak seyir edememesi belirlenen sefer sürelerinin üstüne çıkmalarına neden olmaktadır. Otobüslerin hem tecritli bir şekilde hareket edebilmesi hem de sefer sürelerini tam zamanlı olarak tamamlayabilmeleri için otobüs şeridi uygulamasının Erzurum merkez yollarında kullanılması gereklidir. Otobüs şeridi uygulamasına ek olarak bütün araçlar için kavşaklarda kullanılabilecek diğer bir uygulama ise akıllı kavşak yönetim sistemidir. $\mathrm{Bu}$ sistemde araçlarının sinyalize kavşaklarda bekleme süresinin düşürülmesi ve trafik içerisinde akıcılığının artırılması sağlanabilir. Otoparklara yakın yerlerde kurulacak olan toplu taşıma duraklarına erişilmesi için bisiklet yollarının planlı bir şekilde yapılması, yürüyüş yollarının yapılması, engelliler için gerekli özelliklere sahip yolların yapılması gibi önlemler toplu taşıma kullanımına olan cazibeyi artıracaktır. Ayrica otoparkların doluluk oranların, ücretlerini ve bulunduğu konumdan hangi toplu taşıma sistemlerini aktarma olanağ olduğu gibi konuların AUS kullanılarak mobil uygulamalar ile sürücüye iletilmesi gerekmektedir. $\mathrm{Bu}$ sayede kişisel araç kullanıc1ları otoparklarda park yeri bulma stresi ve karmaşıklığı yaşamayacaktır. Böylece toplu taşıma kullanımına yönlendirici önemli bir adım atılmış olacaktır.

\section{Sonuçlar}

Tüm Dünyada kullanılan ve günlük hayatın vazgeçilmez bir unsuru olan toplu taşıma sistemleri beraberinde birçok problemi meydana getirmektedir. $\mathrm{Bu}$ problemlerin çözülmesi için her geçen gün farklı fikirler karşımıza çıkmaktadır. Bu kapsamda teknolojinin hayatımıza girmesiyle birlikte ortaya çıkan Akıllı Ulaşım Sistemleri toplu taşıma adına birçok probleme çözüm üretebilmektedir. Üretilen çözümler sayesinde toplu taşıma daha cazip hale gelip daha verimli kullanılabilmektedir. Toplu taşımadaki verimin fazla olması durumunda 
en büyük problemlerden biri olan trafik sıkışıklığı azalmaktadır. Toplu taşımadaki verimin artmasiyla birlikte vakit tasarrufu ve ekonomik tasarruf da sağlanmış olacaktır. Öte yandan trafikteki taşıt sayısının azalması zararlı gaz emisyonunu da azaltmaktadır. Tüm bu kazanımlar düşünüldügünde toplu taşımaya yönelik çalışmaların artırılması gerekmektedir. Fakat AUS kapsamında toplu taşıma çeşitliliğinin Erzurum'da az olması ve arzu edilen konfor seviyesinin henüz yakalanamamış olması bu kentte toplu taşıma kullanımının artmasını engellemektedir. Gün geçtikçe artan ulaşım talep miktarı araç sahipliğinin artmasına neden olmaktadır. $\mathrm{Bu}$ yüzden Erzurum'da yerel yönetimler tarafından AUS'a yönelik çalışmalar öncelikli politikalar haline gelmelidir. Ayrıca ülke bazlı düşünüldüğünde ise İstanbul haricindeki şehirler AUS konusunda gelişmiş ülkelerin bir hayli gerisinde kalmıştır. Bu doğrultuda özellikle Ulaştırma Bakanlığı ve belediyeler, AUS'un uygulanması konusunda teşvik edilmeli ve gerekli maddi destekler sağlanmalıdır.

\section{Kaynaklar}

Büyükbaş, N. 2016. Toplu taşıma kullanımını artırıcı uygulamalar ve Kayseri örneği, Yüksek Lisans Tezi, Bahçeşehir Üniversitesi Fen Bilimleri Enstitüsü, İstanbul.

Bursa Büyükşehir Belediyesi Akıllı Şehir Bursa, http://akillisehir.bursa.bel.tr/, Son erişim tarihi: 25.11.2018

Çapalı, B. 2009. Akıllı ulaşım sistemleri ve Türkiye'deki uygulamaları, Yüksek Lisans Tezi, Süleyman Demirel Üniversitesi Fen Bilimleri Enstitüsü. Isparta

Elavarasi, R., Senthilkumar, P.K. 2017. Ak1ll park sistemi, Indian Journal of Science and Technology. 10:9.public transportation system of high quality in Taiwan. 13th COTA International Conference of Transportation Professionals, 1950-1961, China.
Güngör, A., Özturk, E. 2017. Otopark sistemlerinde İstanbul kart uygulamasi ispark örneği. İstanbul Ticaret Üniversitesi Fen Bilimleri Dergisi, 16(31), 73-84.

Hanai, T. 2013. Intelligent Transport Systems: Tokyo, Society of Automotive Engineers of Japan.

İBB. 2017 Y11 Faaliyet Raporu, https://www.ibb.istanbul/SitePage/Inde $\mathrm{x} / 176$, Son erişim tarihi: 26.08.2017

Jasunova, L., Cicmancova, S. 2015. improving safety of transportation by using Intelligent Transportation System. 9th International Scientific Conference Transbaltica, Zilina, Slovakia.

Köz, A. 2011. Akıllı Ulaşım Sistemlerinin kent içi uygulamaları; İstanbul örneğinin değerlendirilmesi. Yüksek Lisans Tezi, Bahçeşehir Üniversitesi Fen Bilimleri Enstitüsü. İstanbul

Kuşkapan, E., Atalay, A, Alemdar, K.D., Codur, M.Y. 2018. Kent İçi Otopark Yönetiminde Akıllı Ulaşım Sistemleri Uygulamaları: Erzurum İli Örneği, 1.Uluslararası Akıllı Ulaşım Sistemleri Konferans1, Bandırma Üniversitesi. 279-282.

Lee, J. 2012. Economic growth and transport models chapter 9: ITS (Intelligent Transport Systems). The Korea Transport Institute, Seul.

Lim, S. 2012. Intelligent transport systems in Korea. International Journal of Engineering and Industries, 3(4).

Nowacki, G. 2012. Development and standardization of intelligent transport systems. TransNav: The International Journal on Marine Navigation and Safety of Sea Transportation, 6(3), 403-411.

Noyes, P. 2014. Introduction to ITS, ITS Professional Capacity Building Program, Amerika Birleşik Devletleri. 
Pelletier, M.P., Trépanier, M., Morency, C. 2011. Smart card data use in public transit: A literature review. Transportation Research Part C, (19), 557-568.

Shi, Y., Yang, X. 2013. The public transportation system of high quality in Taiwan, Social and Behavioral Sciences, (96), 1350 - 1361.

Topdağı, S. 2017. Kentiçi toplu taşıma kullanımının akıllı ulaşım sistemleri ile artırılması ve Erzurum örneği. Yüksek Lisans Tezi, Erzurum Teknik Üniversitesi Fen Bilimleri Enstitüsü, Erzurum.

TÜIK, 2013 y1lı İllere göre belediye hizmetlerinden çöp ve çevresel atık toplama, kanalizasyon, şebeke suyu ve toplu taşıma hizmetlerinden memnuniyet anketi http://www.tuik.gov.tr/PreHaberBulten leri.do?id=27590

Son erişim tarihi: 11.01.2017

TÜIK, 2017 y1lı Motorlu kara taşıtları istatistikleri http://tuik.gov.tr./PreHaber.do?id=2459 6 , Son erişim tarihi: 29.05.2017

Yardım, M.S., Aky1ldız, G. 2004. Ak1llı Ulaştırma Sistemleri ve Türkiye'deki uygulamalar. Türk Mühendis ve Mimar Odaları Birliği (TMMOB) Ulaştırma Politikaları Kongresi, Bildiriler Kitabı, Ankara, $411 \mathrm{~s}$.

Yıldırım, İ. 2016. Afet acil durum yönetimi ile ilgili akıllı ulaşım sistemleri uygulamaları üzerine bir araştırma. Yüksek Lisans Tezi. Bahçeşehir Üniversitesi Fen Bilimleri Enstitüsü. 